\title{
Virchows Archiv: Quo vadis?
}

\author{
Fred T. Bosman
}

Received: 16 November 2011 / Accepted: 16 November 2011 / Published online: 10 January 2012

(C) Springer-Verlag 2012

Each time I receive an issue of Virchows Archiv (The European Journal of Pathology), I realise with a feeling of pride that I am part of an incredible tradition in medical publication: 165 years of continuous pathology publishing! The journal was founded by our intellectual forebear Rudolf Virchow as 'Archiv für Pathologische Anatomie und Physiologie und für Klinische Medicin' in 1847. The first change in name occurred in 1903 when, for the 171 st volume, the name of the founder was added to the name of the journal. Thus it became 'Virchows Archiv fuer Pathologische Anatomie und Physiologie und für Klinische Medizin'. With foresight the editors of the journal in 1968 decided to create two different sections of the journal: volume 344 had part A dedicated to 'Pathologische Anatomie und Histologie' and part B dedicated to 'Zellpathologie', later changed into 'Pathological Anatomy and Histology' and 'Cell Pathology'. These changes anticipated the important impact that the development of molecular biology would have on our understanding of the mechanisms involved in disease and the implications of this knowledge for the practice of diagnostic histo- and cytopathology. The journal also started to accept papers written in English, which in the second half of the twentieth century had become the new 'lingua franca' of science. Just a decade later, English became the sole language for the journal, with another name change: the German name versions disappeared. Again with foresight, the designation 'Molecular Pathology' was added to part B. In 1994, another decade later-we were now at

\section{F. T. Bosman ( $\triangle)$}

University Institute of Pathology, Lausanne University Hospital,

Rue du Bugnon 25,

1011 Lausanne, Switzerland

e-mail: fred.bosman@chuv.ch volume 424 - the two sections were fused, underlining the notion that cellular and molecular mechanisms of disease are an intricate part of pathology, be it in research or in diagnostic practice. The global orientation of the journal was reflected in the subtitle 'An International Journal of Pathology'. In 1999 the journal became officially associated with the European Society of Pathology and, with volume 454 in 2009, the journal metamorphosed in appearance (some like the flashy almost psychedelic colours, others do not) and again in name: the subtitle became 'The European Journal of Pathology'.

I have accepted the invitation to take over as editor in chief from January 2012. I stand in awe of those who have brought the journal to where it is today. Great names from the past such as Lubarsch, Hamperl, Uehlinger, Doerr, Seifert and, in recent decades, Victor Gould, Sir Colin Berry, Philipp Heitz, Manfred Dietel, Vincenso Eusebi, Günter Klöppel, who ran the journal from 1994 to 2003, Pierre Bedossa; the three latter names still being on the list of managing editors. Last but not least, Heinz Höfler, the outgoing editor in chief. We owe an immense, respectful debt of gratitude to Heinz for the energy with which he has handled the journal and his vision, whereby he has brought the journal to its present position: at the forefront of pathology publishing in an era of rapid change, in terms of both the transformation in publishing and the molecular revolution in biomedicine.

The fun part of taking on this responsibility is the opportunity to reflect on the future and to endeavour to maintain the journal in the mainstream of pathology publishing in these very dynamic times. A group of dedicated pathologists came together in the summer of 2011 to anticipate the future of pathology and the directions the journal would need to take to remain in that 
mainstream. So what came out of this? What should the identity of the journal be? Where do we want to go?

Quite a bit of time was spent on a discussion regarding the mission statement: 'To advance the scientific basis of human pathology by the publication of high quality research (including molecular and translational studies) and thereby contribute to patient care.' Publication should be regarded in this context not as passive waiting for submitted papers but actively encouraging new generations of pathologists to engage in scientific observation and to publish their data, as well as the active dissemination of new findings in the electronic age. We also set out to define the type of manuscript that would be characteristic of the journal's content. Evidence-based pathology was chosen as the essential prerequisite: 'Manuscripts of original studies reinforcing the evidence base of modern diagnostic pathology, using immunocytochemical, molecular and ultrastructural techniques, will be welcomed. In addition, papers on the critical evaluation of diagnostic criteria but also broadsheets and guidelines with a solid evidence base will be considered. Consideration will also be given to reports of work in other fields relevant to the understanding of human pathology as well as manuscripts on the application of new methods and techniques in pathology.' Purely experimental pathology, as important as it remains for understanding mechanisms of disease, will not be one of the core interests of the journal. 'Submission of purely experimental articles is discouraged but manuscripts on experimental work applicable to diagnostic pathology are welcomed.' In this era of personalised medicine, biomarker studies will be of increasing importance and therefore 'Biomarker studies are welcomed' when they follow stringent methodological principles 'but need to abide by strict rules (e.g. REMARK - the NCI/EORTC reporting recommendations for tumour marker prognostic studies) of adequate sample size and relevant marker choice. Single marker studies on limited patient series without validated application will as a rule, not be considered.' This will include retrospective histopathological analysis of tissue from prospective studies, notably from tissue samples collected in the context of clinical trials. Unique case studies can be exciting and enlightening but 'Case reports will only be considered when they provide substantial new information with an impact on understanding disease or diagnostic practice.' So these will be the guiding principles for the future development of the journal.

Obviously, what authors and editors want is only one side of the coin. Readers should have an important voice in determining the content of the journal and a readership survey will be circulated shortly. When the message arrives in your mailbox, please do not delete it right away but take a few minutes to complete it; we need your input. To make you aware of what the journal publishes an email alert with a table of contents will be sent out to all subscribers and all others who enlist for this service. To increase interest in original papers published in the journal an annual Virchows Archiv, prize will be awarded: a short list of outstanding papers will be voted on by the editorial board and the prize will be awarded at the annual European Congress of Pathology. To attract more attention to good papers we publish, there will be an effort to improve their titles and to make the abstracts more informative. So do not be surprised if the editorial office suggests a more declarative title for your accepted paper. To lure potential authors to Virchows Archiv, members of the editorial team will actively solicit papers at European Congresses and European Society of Pathology courses. As others have done (we do not pretend to be totally original), we will publish an annual review issue as of 2013. The topics of the annual review issues will have a strong evidence-based pathology/guideline orientation. There will be a few new 'fun' items; for example, we will publish facsimiles of papers published by our intellectual ancestors over the last 50-100 years. We are seriously considering a 'News and views' section at the beginning of the journal. The journal would like to be informative to a broad readership and to keep that readership abreast of what is new out there; this will be the primary goal of this new section. Other ideas are to increase the visibility of the journal through a Facebook page and an item in Wikipedia. My grandchildren use these social media and even I have realised their potential and would like them to be able to appreciate what our discipline is all about.

You might think 'ambitions, ambitions, let us wait and see what happens.' You are right. Making plans is easy. Getting to where we want to be will take a lot of energy. I am fortunate not to have to do this all by myself. A skilled and dedicated editorial team is there to actively contribute. A partially renewed crew of editorial board members will be challenged to participate in this adventure. An office and a dedicated and experienced secretary (Dagmar Schmöe, what would we be without her?) provide essential infrastructural support. The Springer office is on board. But we need you out there: the author to share new knowledge through publishing in Virchows Archiv; the reader to digest its content, apply it in practice and comment or initiate new studies. For all of us this is going to be a fascinating adventure. 